Addendum

\title{
Addendum: Hochreiter, B.; Pardo-Garcia, A.; Schmid, J.A. Fluorescent Proteins as Genetically Encoded FRET Biosensors in Life Sciences. Sensors 2015, 15, 26281-26314
}

\author{
Bernhard Hochreiter $^{\dagger}$, Alan Pardo-Garcia ${ }^{\dagger}$ and Johannes A. Schmid * \\ Institute for Vascular Biology and Thrombosis Research, Medical University Vienna, \\ Schwarzspanierstraße 17, Vienna A-1090, Austria; \\ E-Mails: bernhard.hochreiter@meduniwien.ac.at (B.H.); alanpardogarcia@gmail.com (A.P.-G.) \\ $\dagger$ These authors contributed equally to this work. \\ * Author to whom correspondence should be addressed; E-Mail: johannes.schmid@meduniwien.ac.at; \\ Tel.: +43-1-40160 (ext. 31155); Fax: +43-1-40160 (ext. 931101).
}

Academic Editors: Niko Hildebrandt, Igor Medintz and Russ Algar

Received: 9 November 2015 / Accepted: 10 November 2015 / Published: 18 November 2015

The authors wish to add an Acknowledgments section to their paper published in Sensors [1], doi:10.3390/s151026281, website: http://www.mdpi.com/1424-8220/15/10/26281.

\section{Acknowledgments}

This work was supported by funding from the Austrian Science Fund (projects P-27842 and SFB-F54). Furthermore, the authors wish to specify the correct spelling of the name of the following co-author: Prename: Alan,

Surname: Pardo-Garcia (as double name).

\section{Reference}

1. Hochreiter, B.; Pardo, A.; Schmid, J.A. Fluorescent Proteins as Genetically Encoded FRET Biosensors in Life Sciences. Sensors 2015, 15, 26281-26314.

(C) 2015 by the authors; licensee MDPI, Basel, Switzerland. This article is an open access article distributed under the terms and conditions of the Creative Commons Attribution license (http://creativecommons.org/licenses/by/4.0/). 